\title{
Avaliação da produção de anéis de vedação elastomérica: Estudo de caso em uma
}

\section{empresa do setor automotivo}

\author{
Evaluation of the production of elastomeric sealing rings: A case study in an automotive company \\ Evaluación de la producción de juntas elastoméricas: Un caso de estudio en una empresa del sector \\ de la automoción
}

Recebido: 10/06/2021 | Revisado: 17/06/2021 | Aceito: 25/06/2021 | Publicado: 10/07/2021

\author{
Carlos Augusto Borges da Silva \\ ORCID: https://orcid.org/0000-0003-4422-7883 \\ Universidade Nove de Julho, Brasil \\ E-mail: carlosborges219@gmail.com.br \\ Aparecido dos Reis Coutinho \\ ORCID: https://orcid.org/0000-0002-6686-8828 \\ Universidade Nove de Julho, Brasil \\ E-mail: arcoutin@uni9.pro.br
}

\begin{abstract}
Resumo
De toda a borracha mundialmente produzida voltada ao Mercado Industrial é utilizada para a manufatura de pneus chegando a 70\%. Outra parte da produção é empregada na fabricação de peças automotivas, produtos para os setores médico, de embalagens, construção civil e outros. Na indústria automotiva, destaca se a fabricação de peças empregadas no sistema de condução, componentes para vedação na carroceira, controle e vedação de fluídos de freios, refrigeração, lubrificação, bem como na absorção proveniente dos impactos e força motora. Em grande parte dos componentes elastoméricos de vedações, destacam se os anéis (orings), que são produzidos com materiais e processos específicos de fabricação que variam de acordo com o tipo de vedação em que deverá atuar. Neste contexto, o presente trabalho foi desenvolvido na forma de estudo de caso em uma produtora de vedações elastoméricas destinadas ao Mercado Automotivo. Foram coletados dados relacionados a composição das vedações, quantidade de peças produzidas e importadas pela empresa de suas unidades no exterior, dados relacionas às perdas no processamento da matéria prima e de consumo de energia. Assim os produtos de maior destaque foram os anéis de vedação (orings), com maior proporção na quantidade de peças produzidas, assim como responsável pela maior quantidade de resíduos (scraps) gerados.
\end{abstract}

Palavras-chave: Anéis de vedação; Borracha; Resíduo; Refugo; Energia elétrica.

\begin{abstract}
Most of the industrially produced rubber is used in the manufacture of tires, which corresponds to $70 \%$ of world production. Another part of the production is used in the manufacture of automotive parts, products for the medical, packaging, civil construction and other sectors. In the automotive industry, the manufacture of parts used in the driving system, components for sealing in the car body, control and sealing of brake fluids, cooling, lubrication, as well as in the absorption from impacts and driving force stands out. In most of the elastomeric components of seals, we highlight the rings, which are produced with specific materials and manufacturing processes that vary according to the type of seal in which it should act. In this context, the present work was developed in the form of a case study in a company in the automotive sector, which produces elastomeric seals. Data were collected related to the composition of the seals, the number of parts produced and imported by the company from its units abroad, data related to losses in the processing of raw materials and energy consumption. Thus, the most prominent products were sealing rings (orings), with a greater proportion in the quantity of parts produced, as well as responsible for the greater amount of waste (scraps) generated.
\end{abstract}

Keywords: Sealing rings; Rubber; Waste; Scrap; Electric energy.

\section{Resumen}

La mayor parte del caucho producido industrialmente se utiliza en la fabricación de neumáticos, lo que corresponde al $70 \%$ de la producción mundial. Otra parte de la producción se utiliza en la fabricación de repuestos automotrices, productos para el sector médico, embalaje, construcción civil y otros. En la industria automotriz, se destaca la fabricación de piezas utilizadas en el sistema de conducción, componentes para el sellado de la carrocería, control y sellado de líquidos de frenos, refrigeración, lubricación, así como absorción de impactos y fuerza motriz. En la mayoría de los componentes de estanqueidad elastomérica destacan los anillos (orings), que se producen con materiales y procesos de fabricación específicos que varían según el tipo de estanqueidad en el que deben actuar. En 
este contexto, este trabajo se desarrolló como un caso de estudio en una empresa del sector de la automoción, productora de juntas elastoméricas. Se recopilaron datos relacionados con la composición de los sellos, cantidad de piezas producidas e importadas por la empresa desde sus unidades en el exterior, datos relacionados con pérdidas en el procesamiento de materias primas y consumo de energía. Así, los productos más destacados fueron los anillos de estanqueidad (orings), con una mayor proporción del número de piezas producidas, además de ser los responsables de la mayor cantidad de residuos (desperdicios) generados.

Palabras clave: Juntas tóricas; Goma; Residuo; Chatarra; Energía eléctrica.

\section{Introdução}

De toda a borracha mundialmente produzida voltada ao Mercado Industrial é utilizada para a manufatura de pneus chegando a $70 \%$, em que emprega $10 \%$ de borracha natural (látex), $30 \%$ de borracha sintética, além de $60 \%$ de aço e tecidos (tipo lona), que servem para conformação e rigidez da estrutura. Outra parte da produção é empregada na fabricação de peças automotivas como os anéis de vedação (orings), fabricação de calçados, uso no setor médico, para produção de tubos, luvas cirúrgicas, seringas e embalagens de produtos farmacêuticos (Neto et al, 2019) e outros.

Estudos realizados por Universidades europeias demonstraram que diariamente mais de 2 milhões de pneus são manufaturados mundialmente representando anualmente um número de 730 milhões de pneus produzidos. Por outro lado, 800 milhões de pneus inservíveis são sucateados ou descartados anualmente (Kamimura, 2002). Localmente no Brasil no ano de 2019, 471 toneladas de pneus inservíveis foram descartados e destinados de uma forma ambientalmente correta. Além disso, entre os anos de 1999 e 2019 segundo a Reciclanip, 5,23 milhões de toneladas foram recolhidos e tiveram o seu destino ambientalmente correto compreendendo assim cerca 1,04 bilhão de pneus destinados a automóveis de passeio (Reciclanip, 2021).

Apesar de os pneus serem em volume de borracha a aplicação de maior destaque na indústria automotiva, outras peças deste material são muito importantes na aplicação final veicular, com destaque para fabricação de peças empregadas no sistema de condução, componentes para vedação na carroceira, controle e vedação de fluídos de freios, refrigeração, lubrificação, bem como na absorção proveniente dos impactos e força motora. Também, exemplificando outras aplicações, todo o sistema de arrefecimento veicular, como as juntas de vedação no radiador e mangueiras de condução de água e vapor são manufaturadas a partir da borracha. Geralmente para aplicações em água com alta temperatura é empregado o elastômero de borracha em Etileno Propileno. Este mesmo composto elastomérico é utilizado em outras peças que possuem contato com intempéries e luz solar, como antenas, vedações de portas e vidros, e outros componentes (Aguiar et al, 2020).

\section{Referencial Teórico}

\subsection{Borrachas ao Mercado Automotivo}

A maior parte das borrachas natural e sintética produzidas mundialmente é destinada ao Mercado automotivo. A Figura 1 mostra a evolução e projeção da produção e consumo de borracha natural (Penna \& Jacob, 2016).

Atualmente o Sudeste Asiático é o maior produtor mundial de borracha em torno de 7.3.106 t sendo que a toda a a produção mundial de borracha natural em 2012 foi Algo em torno de 11,3.106 t. Os destaques com relação a maior produção foram a Tailândia com 3,5.106 t (31,00\%), a Indonésia com 3,1.106 t (26,61\%), seguidos pela Índia (8,11\%), Malásia (7,63\%) e Vietnã (7,60\%). No mesmo ano e período, o Brasil produziu apenas 1,5\% da produção mundial o que representou 171,5.103 t. Em 2020 o Brasil produziu 250.103 t, com avanço na produção de borracha natural, porém com potencial de produção estimado em $250.103 \mathrm{t}$ (Abrabor, 2020).

Geograficamente localizada no Sudeste Asiático, a China aparece como a maior consumidora de borracha natural no ano de 2011 chegando a 32,8\% de toda a borracha produzida. A Europa vem em seguida com 11,13\% do consumo da borracha produzida e em seguida vem os Estados Unidos com 9,42\% e o Japão com 7,00\% de todo o consumo. Em termos globais 
países do Sudeste Asiático e Oceania consumiram 60,53\% da borracha natural (Abrabor, 2020).

Figura 1. Evolução e projeção da produção e consumo de borracha natural no mundo.

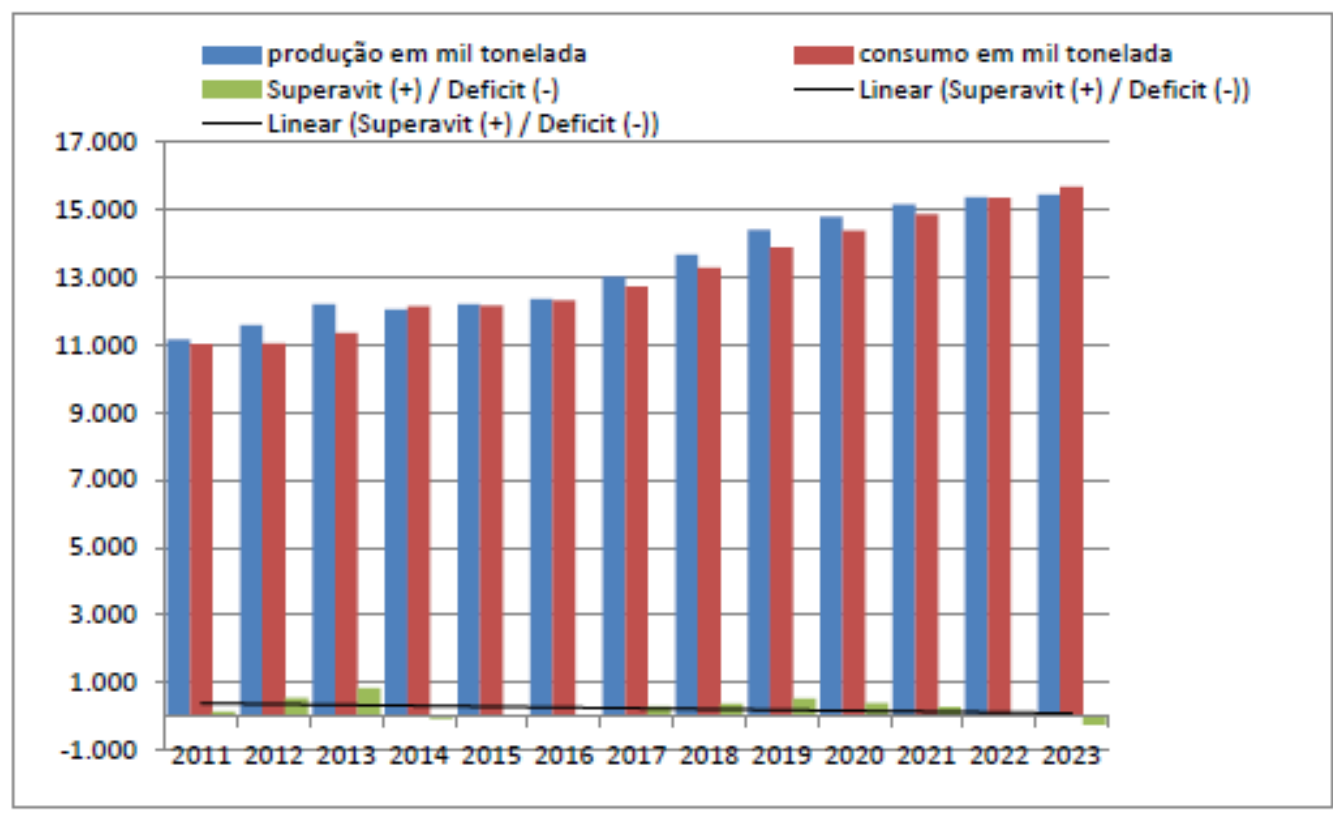

Fonte: Penna \& Jacob (2016)

Apenas na última década 2010-2020 o consumo e a demanda de borracha natural apresentaram o crescimento alinhado ao crescimento da indústria automotiva. O consumo de borracha natural em 2019 no Mundo foi 14,2.106 t superando o ano anterior em 3,7\% (Abrabor, 2020). As projeções de produção, tanto de borracha natural, quanto de veículos automotores relacionados aos anos de 2020 e 2021, foram e ainda estão sendo afetadas fortemente pela pandemia do Novo Corona Vírus, COVID-19. Embora as projeções apontem para crescimento para este setor, ainda não é possível confirmar os dados para os anos-2020-2021.

Apesar dos números voltados aos produtos de borracha serem grande parte destinada aos pneumáticos, existe uma grande participação desta matéria prima em outras aplicações no setor automotivo. Por exemplo, para aplicações no conjunto de condução e contato com combustíveis, como bicos injetores, bombas e tanques são empregadas vedações de borracha com base elastomérica em fluorcarbono, enquanto que em sistema de ar condicionado veicular, é utilizada borracha de nitrílica hidrogenada devido a presença de óleo refrigerante R-134; assim como em função das propriedades físicas e químicas dos materiais. Outro exemplo de aplicação de vedações veiculares no conjunto de amortecimento de impactos, como nos amortecedores, coxins de motor, mancais e retentores de óleo, em que é empregada a borracha com base no elastômero em nitrílica, devido principalmente à elevada resistência mecânica (Aguiar et al, 2020).

\subsection{Anéis de vedação}

Em grande parte dos componentes elastoméricos de vedações, destacam se os anéis orings, que são produzidos com materiais e processos específicos de fabricação que variam de acordo com o tipo de vedação em que deverá atuar. Com relação a forma física, os anéis orings apresentam geometria toroidal, com diâmetros interno e externo, e espessura da parede compatível com o sistema de fixação/alojamento (Figura 2) (Parker Hannifin, 1997). 
Figura 2. Representação gráfica de um anel oring.

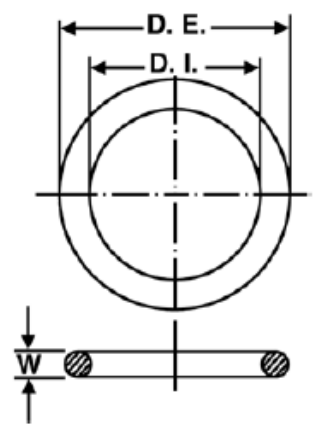

Legenda: D.I. = diâmetro interno; D.E. = o diâmetro externo; $\mathrm{W}=$ secção transversal da parede.

Fonte: Parker Hannifin (1997).

Os orings elastoméricos empregados com propósito de vedação, apresentam como função o bloqueamento, ou fechamento à passagem de fluidos, na forma de líquidos ou gases. O conceito de vedação utilizando orings, parte do pressuposto da instalação de um anel elastomérico dentro de um alojamento (às vezes denominado de compartimento ou canal), utilizando a propriedade de resiliência do elastômero afim de se adequar ao alojamento e evitar com que o fluído à ser vedado passe de um lado para o outro da aplicação (Sun et al, 2009). Mecanicamente falando, o oring preenche as irregularidades do alojamento ou canal se moldando a qualquer folga e fazendo assim que o fluído seja bloqueado e a transferência não ocorra. Assim, a força mecânica comprime o anel oring, fazendo o moldar entre as superfícies de contato, que depende da geometria do alojamento, assim como das propriedades dos materiais, do próprio oring, das superfícies e do fluido. Desse modo, quanto maior a pressão exercida no oring mais efetiva será a aplicação já que se oldará na superfície do alojamento efetuando assim a vedação sempre respeitando os os limites físicos da borracha e evitando assim que o fluido passe entre as partes à serem vedadas (Sun et al, 2009).

\subsection{Processo de produção da borracha}

O Brasil responde por 3\% da produção mundial, com cerca de $12.106 \mathrm{t}$ de borracha sintética. As importações de artefatos de borracha sintética pelo Brasil correspondem em torno de $40 \%$ do consumo doméstico, enquanto que suas exportações representam 40\% da produção nacional, que giram em torno de 150.103 t/ano (Sun et al, 2009).

Para a borracha natural, o látex é extraído por meio de cortes na casca da seringueira em que é feita a retirada de um pequeno volume da seiva por meio de escoamento. Após este processo, o látex é coagulado, em seguida moído e transformado em pasta. $\mathrm{O}$ ciclo de produção da seringueira é de 18 meses para a formação da muda e mais 7 anos até o desenvolvimento da árvore. Uma seringueira pode produzir látex por 30 anos. A safra da produção do látex ocorre no primeiro semestre do ano, em que as usinas de beneficiamento adquirem o coágulo adicionado ao látex e transformam em borracha moída e granulada, empregada como matéria prima pela indústria de borracha (Monbensani, 2019).

A borracha sintética é produzida na segunda geração petroquímica, tendo como matérias-primas básicas o estireno e o butadieno que são originários da primeira geração petroquímica e tem sua origem proveniente da nafta. A figura 3 mostra o diagrama simplificado do processo de produção da borracha sintética. 
Figura 3. Diagrama simplificado do processo de produção da borracha sintética.

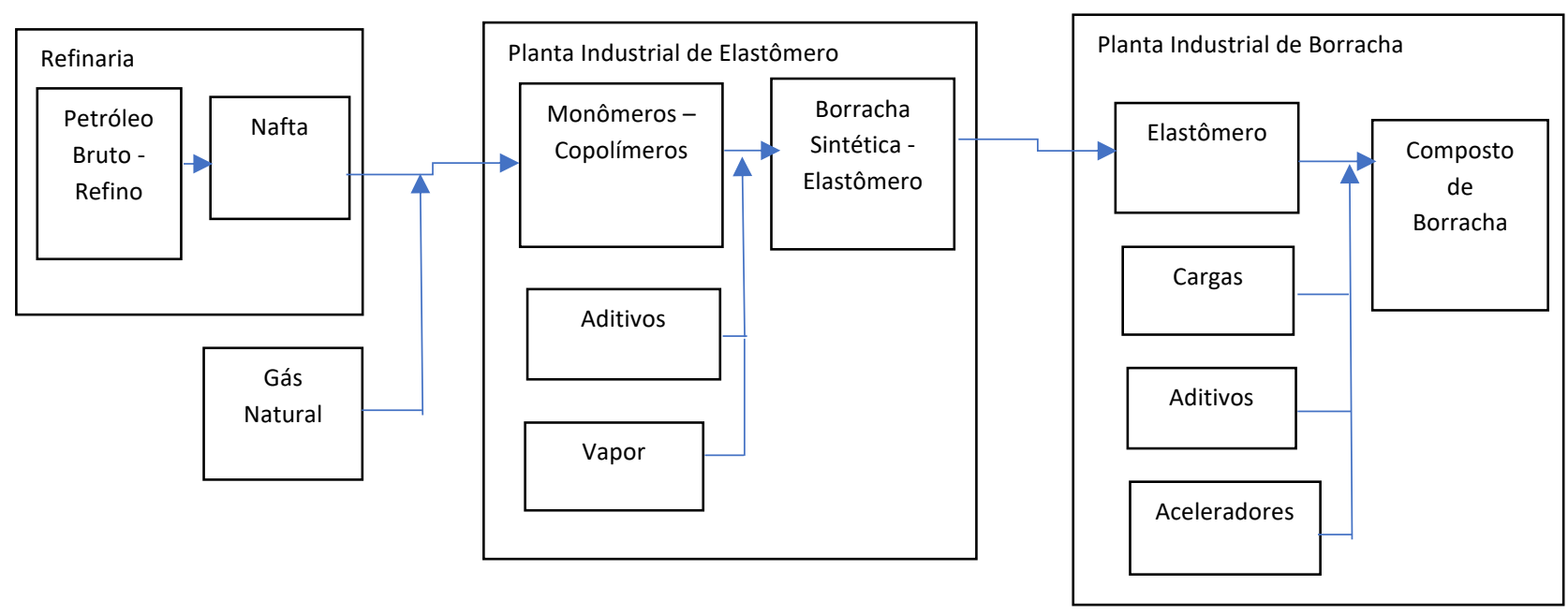

Fonte: Adaptado pelo Autores.

A produção da borracha sintética é relacionada a segunda geração de polímeros já que parte de copolímeros já existentes e denominados monômeros como o estireno e o butadieno onde destacam-se 4 etapas distintas no processo. Nesta primeira etapa é aonde ocorre a mistura dos componentes da borracha sintética como os aditivos, agentes de vulcanização, pigmentos, catalisadores e aceleradores fazendo com que se origine o composto elastomérico (Monbensani, 2019).

A segunda etapa consiste na conformação da mistura através dos processos de extrusão, injeção ou prensagem. Após a etapa de conformação, na terceira etapa o composto elastomérico é submetido à vulcanização, por meio da aplicação de calor e pressão para conferir elasticidade. O processo de vulcanização sempre é realizado em alta temperatura onde o composto adquire suas características químicas e físicas passando do estado plástico para o estado elástico. Aqui também se adquire características físicas como a dureza do composto e sua resistência mecânica. A quarta etapa consiste no acabamento, que varia de acordo com a finalidade do uso da borracha vulcanizada, assim como as exigências dos consumidores e usuários finais como excesso de rebarba admissível e demais pontos discutidos entre as engenharias (Monbensani, 2019).

Além disso, um dos componentes mais presentes na borracha sintética, além dos monômeros, também é derivado da indústria petroquímica, que é o negro de fumo (carbon black), que apresenta elevado teor de carbono e tem a finalidade de conferir dureza e outras propriedades físicas e químicas ao elastômero. Como exemplo, na produção de pneus o carbon black representa em torno de $25 \%$ de sua composição em massa, juntamente com outros polímeros, como o nylon, o poliéster, além de produtos como o aço e lonas especiais (Monbensani, 2019).

\subsection{Avaliação do Ciclo de Vida}

A técnica mais utilizada para a análise de produtos, processos ou serviços é a avaliação do Ciclo de Vida - ACV que consiste em identificar os potenciais impactos ambientais relacionados em todo ciclo de vida, desde o berço ao o túmulo, onde geralmente é utilizado práticas como o balanceamento de massas bem como energia. (Robèrt et al, 2002). Os registros indicam que a primeira aplicação dos conceitos da ACV ocorreu em 1969, voltada para análise ambiental de embalagens de bebidas (Guinée et al, 2012; Sheldon, 2016). Em 1997 foi publicada a norma ISO 14040, estabelecendo conceitos e diretrizes para estudos de ACV (ABNT, 2011), de modo que esta técnica é amplamente utilizada em análises que consideram a interação entre conjuntos de empresas (Daddi et al, 2017; Loiseau et al, 2016), seja para avaliação da viabilidade de um sistema ou para comparação ambiental entre diferentes produtos e processos (Seidel-Sterzik et al, 2018). 
No contexto do ciclo de vida do produto, a Gestão do Ciclo de Vida (GCV) é uma ferramenta gerencial que integra os aspectos ambientais, econômicos e sociais na tomada de decisão, tendo como meta, por exemplo, o desenvolvimento de produtos e processos de produção cada vez mais sustentáveis. As práticas de GCV são importantes na contribuição para a sustentabilidade das organizações, inclusive em empresas de micro, pequeno ou médio porte. Não obstante, a implementação da GCV em sistemas reais ainda está distante de alcançar a abrangência proposta com relação aos conceitos de ciclo de vida (Oliveira et al, 2018), sendo que na maioria dos casos é geralmente utilizada como uma ferramenta de apoio ao desenvolvimento do produto, por equipes de engenharia e design (Cattaneo et al, 2018). Ainda, nem sempre as ações para otimização pontual dos impactos ambientais de um produto resultarão em significativa otimização do sistema como um todo, tornando necessária uma visão sistêmica do ciclo de vida dos produtos. Dessa forma, a GCV pode ser uma abordagem importante no gerenciamento da sustentabilidade e do desempenho de produtos e materiais ao longo das cadeias de manufatura e de valor (Balkau \& Sonnemann, 2019).

Com relação ao ciclo de vida da borracha sintética, inicialmente ocorre a transformação do combustível fóssil em polímero, por meio do refino e da aplicação de nafta, que posteriormente se transforma no monômero que, depois de ser inseridos os aditivos e vapor, se transforma em borracha sintética. A partir do polímero pronto, segue a mistura com Carbon Black, aditivos, aceleradores e outras cargas transformam estes materiais em borracha sintética. Para a conformação da borracha em artefatos, a borracha passa por processos de compressão e injeção, que em alta temperatura são vulcanizados e conformados em peças e componentes, para diversas aplicações (Li, T. \& Li, Q, 2017).

A maioria dos compostos elastoméricos possuem em sua composição diversos componentes. Além do elastômero base que diferencia os tipos de borrachas para as diversas aplicações que serão destinadas, destaca se a incorporação de "cargas"; como o negro de fumo (carbon black); as cargas minerais, que geralmente são utilizadas para características físicas de enchimento, volume e agentes de reforço estrutural; os plastificantes, como os óleos; os aditivos, como os ativadores de aceleração; os anti-oxidantes e os agentes de fluxo que auxiliam a fluidez dos materiais; por fim, os aceleradores, como o enxofre que tem como característica de ser o "fermento" da formulação (Marschner, 1973).

A Tabela 1 mostra, de forma resumida, a participação percentual entre duas famílias de compostos e suas proporções aproximadas de cada componente na formulação; sendo que estas proporções podem sofrer variações em função das aplicações, suas formulações, assim como as propriedades físicas e químicas dos produtos elastoméricos (Marschner, 1973).

Tabela 1. Composição genérica dos elastômeros

\begin{tabular}{|c|c|c|}
\hline Componentes & $\begin{array}{c}\text { Composto } \\
\text { NBR/EPDM/CR }\end{array}$ & $\begin{array}{c}\text { Composto } \\
\text { FKM }\end{array}$ \\
\hline Elastômero Base & $50 \%$ & $92 \%$ \\
\hline Cargas Minerais e/ou Negro de Fumo & $40 \%$ & $6 \%$ \\
\hline Aditivos (ativador, agente de fluxo) & $5 \%$ & $2 \%$ \\
\hline Aceleradores (enxofre) & $5 \%$ & - \\
\hline
\end{tabular}

Fonte: Autores.

A indústria automobilística utiliza em grande escala os compostos a base de NBR devido a sua característica de resistência mecânica e abrasão, assim como sua propriedade química de possuir compatibilidade com óleos a base de petróleo, em ambientes com temperaturas de trabalho que podem variar de $-40^{\circ} \mathrm{C}$ a $120^{\circ} \mathrm{C}$. O composto EPDM é largamente utilizado em aplicações de arrefecimento veicular, que necessita do contato com água ou vapor, em faixas de temperaturas que podem 
variar desde $-30^{\circ} \mathrm{C}$ até $130^{\circ} \mathrm{C}$; além do que deve ser compatível com intempéries para aplicações externas como frisos e antenas. O composto $\mathrm{CR}$ é utilizado em aplicações como coifas e guarda-pós, devido suas características de alongamento e resistência mecânica (Bhattacharya et al, 2020).

O composto FKM (sigla usada para fluorelastômeros, conforme definido na norma ASTM D1418), também conhecido como Fluorcarbono, ou comercialmente chamado de Viton ${ }^{\circledR}$, que é um produto específico da empresa Dupont ${ }^{\circledR}$, apresentam os aceleradores presentes no elastômero base, de modo que não aparecem na proporção explicitada na tabela. Este também é um dos fatores com que fazem que compostos borrachas à base de FKM geralmente apresentam custos comerciais superiores aos demais compostos elastoméricos, além é da maior quantidade de elastômero que é necessário na formulação. Além disso, o Flúor também faz parte do elastômero em FKM, que contribui para elevação do custo deste material, comparado aos demais (Cabrera et al, 2018).

Existem vários trabalhos publicados sobre GCV, principalmente voltados aos impactos ambientais e também a reciclagem de borracha, porém a maioria dos trabalhos está focada no processo de reciclagem, e não no consumo de energia e, como o pneu é ainda o produto que delimita a demanda da borracha mundialmente, a maioria dos trabalhos trazem casos de reutilização e reciclagem deste produto. Como exemplo, o artigo que aborda o impacto ambiental do concreto autoadensável com pneus utilizando a abordagem de GCV (Jorgenson, 2003).

Outro exemplo, a borracha nitrílica é considerada um importante insumo na indústria de borracha automotiva, devido sua resistência química e desempenho mecânico. No entanto, aplicações como mangueiras, vedações ou gaxetas estão sujeitas a danos e desgaste físicos, limitando sua vida útil. Alguns trabalhos trazem uma perspectiva em utilização de novos compostos como a borracha nitrílica carboxilada como uma solução para melhorias de resistência química e mecânica, reduzindo a deterioração e redução da resistência a solventes alifáticos como óleo de motor e gasolina (Barrios et al, 2020).

\section{Metodologia}

Como revisão bibliográfica, foi utilizado a ferramenta Bibliometrix conjugada ao Science Mapping. Baseado na plataforma Scopus foram considerados artigos completos publicados no período compreendido entre 2015-2020, com as palavras chaves: sendo "energy sav" conjugada com a palavra "rubber" onde foram retornados da pesquisa ao todo 64 Artigos relacionados.

Inicialmente, foi feita análise de títulos e resumos dos 64 artigos selecionados, sendo descartados 12 artigos que não estavam na língua inglesa. Após isto, foram também desconsiderados mais 13 artigos em inglês, mas não classificados na plataforma JCR; resultando assim em 39 trabalhos publicados. Na sequência, os 39 artigos foram analisados por completo e descartados os que não tinham relevância com relação ao tema voltado a economia de energia em processos de produção da borracha. Finalmente, restaram oito publicações que apresentaram sinergia com a produção de orings e com o processo de produção de borracha no que tange a economia de energia. Portanto, em função de pouquíssimas publicações, observou que existe uma lacuna de pesquisa no setor da produção de componentes de borracha para o setor automotivo, em especial com relação ao consumo de energia. Ainda, dentre as publicações selecionadas, destaca o artigo "Optimal power management strategy for energy storage with Stochastic loads" (Pietrosanti et al, 2016) que é uma importante fonte de informações técnicas sobre o tema deste trabalho.

Com relação ao estudo de caso, foi feita aquisição de dados do consumo de energia elétrica e do processo de produção de vedações elastoméricas em uma empresa multinacional, que além de vedações automotivas, trabalha com uma extensa linha de produtos voltada para os segmentos hidráulica, pneumática, filtração, mangueiras e conexões e aeroespacial. A divisão de vedações deste grupo multinacional está localizada no Estado na cidade de São Paulo e sua identificação é mantida em sigilo, de modo que neste trabalho será denominada apenas como VEA Peças Automotivas (obs: a sigla VEA = Vedações 
Elastoméricas Automotivas).

Finalmente, o estudo de caso tem como definição ser uma pesquisa empírica investigando um fenômeno dentro de um contexto do mundo real e das empresas, geralmente quando as diferenças entre o fenômeno e o contexto não são claras onde várias evidências podem ser utilizadas (Yin, 2015).

A pesquisa será de natureza qualitativa já que trabalharemos apenas nos pontos coletados de apenas uma empresa conforme descrita acima.

\section{Resultados e Discussão}

Inicialmente, destaca se nos últimos anos ocorreu aumento da comercialização de vedações automotivas importadas de outras plantas da empresa VEA. Este fato implicou na redução de insumos e scrap para confecção das peças no Brasil, que vêm diminuindo ano após ano. Por exemplo, no final do ano de 2019, em torno de $60 \%$ dos produtos que a empresa VEA comercializou de foram de outras plantas, situada em outros países, o que colaborou a diminuição do volume de borracha misturada localmente.

A Tabela 2 mostra a composição média dos custos envolvidos na produção das vedações elastoméricas no período compreendido entre 2017-2019, pela empresa VEA. Os dados mostram que as principais despesas de produção estão relacionadas à aquisição e processamento das matérias primas, juntamente com os custos de mão de obra; seguidos pelos gastos com energia elétrica.

Tabela 2. Composição dos custos de produção das vedações elastoméricas.

\begin{tabular}{lc}
\hline Insumos & \% no custo \\
\hline Matérias primas & $40 \%$ \\
Mão-de-Obra & $40 \%$ \\
Energia Elétrica & $15 \%$ \\
Despesas gerais de fabricação & $5 \%$ \\
\hline TOTAL & $\mathbf{1 0 0 \%}$ \\
\hline
\end{tabular}

Fonte: Autores.

A Tabela 3 mostra a quantidade de peças elastoméricas, produzidas no ano de 2019, assim como as importadas pela VEA de suas próprias unidades localizadas em outros países, em que os anéis orings e as juntas de vedação representam a maior proporção em produção. Os destacados como "outros" geralmente são peças customizadas que não eram direcionadas para vedação, como passa-cabo, batentes, coxins, etc.

Tabela 3. Quantidade de peças produzidas no ano de 2019

\begin{tabular}{lcc}
\hline Linha de produtos & Peças produzidas & Peças importadas \\
\hline Orings & 5.788 .904 & 9.073 .959 \\
Juntas de vedação & 986.800 & 325.977 \\
Retentores & 0 & 55.256 \\
Outros & 425.318 & 1.355 .464 \\
\hline Total & $\mathbf{7 . 2 0 1 . 0 2 2}$ & $\mathbf{1 0 . 8 1 0 . 6 5 6}$ \\
\hline
\end{tabular}

Fonte: Autores. 
A maioria dos artigos científicos relacionados as borrachas destinadas ao mercado automotivo, assim como os componentes/peças produzidos pela VEA são compostos com base em nitrílica. Ainda, destaca se que a VEA emprega maior quantidade de matérias primas no processo de produção das vedações automotivas, tendo como justificativa as perdas inerentes às etapas de conformação da borracha. Assim, os resíduos, ou as rebarbas relacionadas a conformação são descartadas, pois o processo de vulcanização impede que sejam reutilizadas para produção de novas peças. Desse modo, em torno de $50 \%$ da matéria prima e insumos misturados no processo VEA não é destinado ao produto final, e sim ao excesso de material necessário para a conformação dos itens por ela manufaturados. Ainda, a diferenciação de qual processo utilizar geralmente está ligada ao volume do item a ser manufaturado. Assim, quanto maior o volume, são empregadas máquinas injetoras que possuem alimentação automática de matéria-prima, que permite reduzir ciclo de produção. Por outro lado, a conformação pode ser feita de duas formas: a alimentação manual da matéria-prima nos moldes da prensa; ou por meio da conformação por extrusão.

Com relação às características, os anéis orings são produzidos em dimensões variadas, para as mais diversas aplicações. Tomando se como base a variedade e quantidade de peças manufaturadas, peso médio estimado é de 0,786 gramas por peça manufaturada. Portanto, considerando as 5.788 .904 peças manufaturadas no ano de 2019 pela VEA, e considerando que $80 \%$ da borracha misturada foi direcionada para esta linha de produtos, então VEA misturou neste ano cerca 9,1 toneladas do composto elastomérico nitrílica. Assim, a Tabela 4 apresenta a quantidade de matérias primas e insumos empregados para a produção desta quantidade de anéis orings.

Tabela 4. Proporção matérias primas empregadas na produção de anéis orings.

\begin{tabular}{lcc}
\hline Insumos & Composto & Quantidade (t) \\
\hline Elastômero base & $50 \%$ & 4,55 \\
Cargas minerais e Negro de Fumo & $40 \%$ & 3,64 \\
Aditivos (ativador, agente de fluxo) & $5 \%$ & 0,46 \\
Aceleradores (enxofre) & $5 \%$ & 0,46 \\
\hline Total & $\mathbf{1 0 0 \%}$ & $\mathbf{9 , 1}$ \\
\hline
\end{tabular}

Fonte: Autores.

Outro fator de destaque é com relação as perdas que ocorrem no processo de produção. Além da perda na forma dos resíduos gerados (galhos e rebarbas), existem dois tipos diferentes de refugo, ou scrap: que são as peças descartadas e reprovadas durante o processo, e as peças inservíveis resultantes da inspeção final dos produtos finalizados. Nesse caso, o número atualizado de scrap de inspeção na VEA gira em torno de 2,5\% de todo o volume de borracha prensada, relacionada ao peso apenas dos orings; enquanto que o scrap de inspeção para o processo de compressão gira em torno de 3,2\% de produtos, que serão descartados por não atingir os critérios finais, tanto em dimensional quanto em acabamento.

Além disso, a borracha uma vez vulcanizada não pode ser novamente utilizada, pois o processo de alta temperatura empregada faz com que os componentes para vedações atinjam características físicas e químicas definidas, fazendo com que descarte de todas as peças de scrap seja integral. Algumas outras empresas utilizam sobras de processos de borrachas para confecção de produtos não destinados a vedação, tendo sem em vista a necessidade do controle de fluxo e temperatura para um vedante deve ser muito mais criterioso. Assim, por exemplo, peças como tapetes, buchas e componentes não vedantes, podem produzidas a partir do scrap como matéria-prima de borracha recuperada, nesse caso, podendo ser empregada no contexto da economia circular para borracha. A Tabela 5 mostra a representatividade do scrap de matérias-primas, empregadas na produção de anéis orings sem carga adicional, ou seja, scraps de peças recusadas/dispensadas pela VEA anualmente. 
Tabela 5. Total de borracha descartada para Orings pela empresa VEA

\begin{tabular}{cccccc}
\hline Ano & $\begin{array}{c}\text { \% Produtos } \\
\text { manufaturados }\end{array}$ & $\begin{array}{c}\text { Quantidade de } \\
\text { borracha misturada } \\
\text { (4,55 t/ano) }\end{array}$ & $\begin{array}{c}\text { Scrap de } \\
\text { processo (2,5\%) }\end{array}$ & $\begin{array}{c}\text { Scrap de } \\
\text { inspeção (3,2\%) }\end{array}$ & $\begin{array}{c}\text { Total de } \\
\text { scrap (Kg) }\end{array}$ \\
\hline 2017 & $61 \%$ & 2,78 & 71,28 & 91,90 & 163,2 \\
2018 & $49 \%$ & 2,23 & 57,18 & 73,72 & 130,9 \\
2019 & $40 \%$ & 1,82 & 46,67 & 60,17 & 106,8 \\
\hline
\end{tabular}

Fonte: Autores.

Portanto, a perda de 4,55 t/ano na forma de resíduos (galhos e rebarbas) no processo de produção, somadas a 0,11 t/ano de scrap totaliza 4,66 t/ano de material que precisa ser descartado de forma ambientalmente correta e sustentável. Assim, para este descarte, a empresa VEA subcontrata uma empresa de coleta de resíduos que revende esta borracha para outras empresas manufaturadoras de peças voltadas a tapetes, borrachas moídas e trituradas para a construção civil e demais aplicações, de modo que esta coleta segue todas legislações regulatórias de descarte de resíduos.

$\mathrm{Na}$ manufatura das vedações elastoméricas, grande parte da energia consumida no processo de transformação ocorre nas etapas de injeção, compressão e na vulcanização da borracha por meio da aplicação de calor e pressão. Em geral, a vulcanização ocorre entre $150^{\circ} \mathrm{C}-180^{\circ} \mathrm{C}$, em que o material passa do estado plástico para o elástico, alterando suas propriedades físicas e químicas, como dureza, resistência mecânica e elasticidade. Para isto, independentemente do processo, tanto as injetoras de borracha quanto as prensas de compressão utilizam resistências para geração de calor o que implica em grande consumo de energia elétrica. A VEA possui 28 prensas de platôs duplos totalizando 56 platôs e 8 injetoras. Cerca de $70 \%$ da energia elétrica consumida total da empresa é direcionada para o processo de moldagem e compressão.

As Prensas são da marca Panstone, modelos de compressão à vácuo com força de fechamento de $350 \mathrm{t}$ e dois platôs de 700 x $700 \mathrm{~mm}$, com uma potência de 55,41 KW e motor com $25 \mathrm{CV}$, que opera em dois turnos, completando assim 14 horas diárias de funcionamento. O consumo mensal de energia elétrica neste setor é de $477.856 \mathrm{KWh} / \mathrm{mês}$. A empresa implantou projetos para redução de scrap, por meio do uso de novas alternativas de moldes e ferramentas necessárias para a conformação dos anéis de vedação; de modo que os moldes com processo de flashless (sem rebarbas) conseguem diminuir as perdas no scrap de processo em até $1 \%$ dentre os $2,5 \%$ perdidos, o que resulta na redução de $4.779 \mathrm{KWh} /$ mês do consumo de energia, tendo se em vista que em função volume manufaturado, tem se o valor de 0,083 KW mês/peça. Outro projeto visando a diminuição de scrap é no processo de extrusão e corte, utilizando novas extrusoras com corte a laser dos tubos de borracha e melhor controle de gramatura, que também contribui para redução do consumo estimado de energia de $15.000 \mathrm{KWh} / \mathrm{mês}$.

\section{Conclusão}

Os dados obtidos, na forma de estudo de caso na empresa VEA, mostraram que os anéis (orings) representam a maior proporção dentre as peças produzidas, assim como entre as importadas pela própria empresa de suas unidades no exterior.

Com relação aos resíduos da produção dos anéis orings, observou se que são gerados em torno de $2,5 \%$ de scrap de todo o volume de borracha prensada, enquanto que o scrap de inspeção é da ordem de 3,2\% de produtos, que são descartados por não atingir os critérios finais, tanto em dimensional quanto em acabamento. Esta proporção representa uma perda de 4,66 t/ano de material que precisa ser descartado de forma ambientalmente correta e sustentável, além do que parte destes resíduos são remanufaturados para produção tapetes, borrachas moídas e trituradas para a construção civil.

Outro fator de destaque corresponde ao consumo médio mensal de energia elétrica que atinge em torno de 477.856 
$\mathrm{KWh} /$ mês, sendo que as etapas de injeção, compressão e vulcanização as responsáveis por maior proporção no consumo total.

Os dados apresentados serão complementados em um segundo trabalho, no campo da Economia Circular, em que serão coletados os custos das matérias-primas, de energia, de mão-de-obra, além de mensurar todos os descartes, o reuso de componentes inservíveis, e outros.

Como sugestão para trabalhos futuros, a replicação de levantamento de informações de energia elétrica em outras empresas manufaturadoras de anéis de vedação pode ser muito bem recomendada afim de contrapor com as informações levantadas na empresa estudada no Estudo de Caso e identificar boas práticas e soluções que podem ou não serem utilizadas em outras empresas de elastômeros.

\section{Referências}

ABNT NBR ISO 14040. (2001). Avaliação do ciclo de vida - Princípios e estrutura. Associação Brasileira de Normas Técnicas.

ABRABOR - Associação Brasileira de Produtores e Beneficiadores de Borracha Natural. (2020). http://www.agricultura.gov.br/assuntos/camaras-setoriais/

Aguiar, R. P. A., Almeida, O., Gonçalves, C., (...), Santos, H. \& Souza, J. (2020). The Effect of Biodiesel on the Electrical Properties of Automotive Elastomeric Compounds, SAE Technical Papers.

Balkau, F. \& Sonnemann, G. (2010). Managing sustainability performance through the value-chain. Corporate Governance, 10 (1), $46-58$.

Bhattacharya, A. B., Chattrjee, T. \& Naskar, K. (2020). Automotive applications of thermoplastic vulcanizates. Journal of Applied Polymer Science. 137, doi:10.1002/app.49181.

Barrios, S., Morera, J., Reyes, L., \&, Santana, M. (2020). An effective and sustainable approach for achieving self-healing in nitrile rubber. European Polymer Journal, 139, 1-12.

Cabrera, L. I. F., Gonzàles, J. P. \& Hernandèz, E. A. G. (2018). Deterioration of seals of automotive fuel systems upon exposure to straight Jatropha oil and diesel. Renewable Energy, 127, 125-133.

Cattaneo, L., Cassina, J., Petrucciani, M., Terzi, S. \& Wellsandt, S. (2018). Models, Methods and Tools for Product Service Design. Springer.

Daddi, T., Nucci, B. \& Iraldo, F. (2017). Using Life Cycle Assessment (LCA) to measure the environmental benefits of industrial symbiosis in an industrial cluster of SMEs. Journal of Cleaner Production, 147, 157-164.

Guinée, J. B., Heijungs, R., Huppes, G., Zamagni, A., Masoni, P., Buonamici, R., Ekvall, T. \& Rydberg, T. (2011) Life Cycle Assessment: Past, present, and future. Environmental Science Technology, 45 (1), 90-96.

Jorgenson, L. (2003). Asphalt rubber pavement construction. Public Works, 134 (1), 30-31.

Kamimura, E. (2002). Potencial de utilização dos resíduos de borracha de pneus pela indústria da construção civil. Dissertação de Mestrado do Programa de Pós-Graduação em Engenharia Civil, UFSC. p. 128.

Li, T. \& Li, Q. (2017). The carbon footprint analysis of tire throughout the life cycle in China. JP Journal of Heat and Mass Transfer, 14(3), 421-443.

Loiseau, E., Saikku, L., Antikainen, R., Droste, N., Leskinen, P., Kuikman, P., Hansjurgens, B., Pitk, K. \& Thomsen, M. (2016). Green economy and related concepts: An overview. Journal of Cleaner Production, 139, 361-371.

Marschner, G. (1973). Nitrile Rubber - Black Masterbatches. [nitrilkautschuk-russ-masterbatches.] Gummi Asbest Kunstst, 26 (5), $408-409$.

Monbensani. (2020). Acessado em 10 Nov, 2020, de http://infocarmobensani.com.br/pitstop-mobensani/fabricacao-da-borracha-materia-prima-de-altaqualidade/

Neto, G.C.O., Chaves, L.E.C., Pinto, L.F.R., Santana, J.C., Amorim, M.P.C. \& Rodrigues, M.J.F. (2019). Economic, environmental and social benefits of adoption of pyrolysis process of tires: a feasible and eco-friendly mode to reduce the impacts of scrap tires in Brazil (2019). Sustainability, 11 (7), doi: 10.3390/su1102076.

Oliveira, C. G. H., Silva, D. A. L. \& Oliveira, J. A. A. (2018). Gestão do ciclo de vida (GCV) para a sustentabilidade de pequenas e médias empresas (PMEs) na região de Sorocaba/SP: principais entraves e desafios. Revista Latino-Americana em Avaliação do Ciclo de Vida, 2, 23-47.

Parker Hannifin. (1997). Manual de O’rings. Catálogo 5700-BR. São Paulo.

Penna, R. \& Jacob, J. (2016). Desequilíbrios entre oferta e demanda derrubam preços do Látex. Revista Safra, 18 (189), $23-26$.

Pietrosanti, S., Holderbaum, W. \& Becerra, V. (2016). Optimal power management strategy for energy storage with stochastic loads. Energies, 13 (10), doi:10.3390/en9030175.

Reciclanip. (2021). https://www.reciclanip.org.br/destinados/ 
Research, Society and Development, v. 10, n. 8, e16410817040, 2021

(CC BY 4.0) | ISSN 2525-3409 | DOI: http://dx.doi.org/10.33448/rsd-v10i8.17040

Robèrt, K. H., Schmidt-Bleek, B., Aloisi de Larderel, J., Basile, G., Jansen, J. L., Kuehr, R.; Price Thomas, P., Suzuki, M., Hawken, P. \& Wackernagel, M. (2002). Strategic sustainable development - Selection, design and synergies of applied tools. Journal of Cleaner Production, 10 (3), $197-214$.

Seidel-Sterzik, H., Mclaren, S. \& Garnevska, E. (2018). Effective Life Cycle Management in SMEs: Use of a Sector-Based Approach to Overcome Barriers. Sustainability, 10 (2), doi:10.3390/su10020359.

Sheldon, R. A. (2016). The E factor 25 years on: the rise of green chemistry and sustainability. Green Chemistry, 19 (1), $18-43$.

Sun, F., Yu, T., Cui, W. \& Zong, X. (20019). The seal reliability analysis of oring seals. Proceedings of 2009 8th International Conference on Reliability, Maintainability and Safety, p. 1293

Yin, R. (2015). Case Studies. International Encyclopedia of the Social \& Behavioral Sciences. 2, 194-201. 